\title{
Multiscale Tomographic Analysis of the Thermal Failure of Na- Ion Batteries
}

\author{
James B. Robinson ${ }^{1}$, Thomas M.M. Heenan ${ }^{1}$, J. Rhodri Jervis ${ }^{1}$, Chun Tan ${ }^{1}$, Emma Kendrick ${ }^{1}$, \\ ${ }^{2,3}$, Dan J. L. Brett ${ }^{1}$ and Paul R. Shearing ${ }^{1 *}$ \\ ${ }^{1}$ Electrochemical Innovation Lab, Department of Chemical Engineering, UCL, London, UK, WC1E 7JE \\ ${ }^{2}$ Warwick Manufacturing Group, University Road, University of Warwick, Coventry, UK,CV4 7AL \\ ${ }^{3}$ School of Chemistry, University of Birmingham, Edgebaston, Birmingham, UK, B15 2TT \\ * Author to whom correspondence should be addressed \\ Web: www.ucl.ac.uk/electrochemical-innovation-lab \\ Email: p.shearing@ucl.ac.uk
}

\begin{abstract}
In recent years, the ability to examine the processes that cause the catastrophic failure of batteries as a result of thermal runaway has improved substantially. In this work, the effect of thermal runaway on the microstructure of the electrodes of a Na-ion battery is examined using X-ray computed tomography for the first time. The thermal failure induced via accelerating rate calorimetry enabled the examination of failed electrodes, which were subsequently compared with fresh samples. Microstructural analysis shows changes in both electrodes as a result of the thermal runaway process at the micrometre length-scale. It is seen that the cathode shows the largest changes in structure, with the anode remaining morphologically similar post-failure at the sub-micron length-scale. The formation of a highly X-ray attenuating layer, which is proposed to be a metallic product of the thermal
\end{abstract}


runaway reaction, is observed, indicating that the thermal runaway mechanisms which occur in Na-ion batteries may be similar to those reported for Li-ion systems.

\section{Keywords}

Thermal runaway; Na-ion battery; X-ray computed tomography; microstructural analysis; battery failure; accelerating rate calorimetry.

\section{Introduction}

At present, the Li-ion cell is the predominant system used in devices ranging from mobile telephones to electric vehicles. Whilst the safety of Li-ion cells has been greatly improved since their initial deployment, this cell-type has also been implicated in a number of high profile failures [1-4]. Additionally, the relatively high cost of materials [5] and concerns over the long-term supply of $\mathrm{Li}$ [6] has resulted in continued interest in developing and commercialising new cell chemistries. One such technology is the Na-ion battery, which alleviates some of these concerns due to the low cost, global distribution and abundance of $\mathrm{Na}$ [7], has recently attracted considerable interest [8]. Further benefits of Na-ion cells can be found by using an $\mathrm{Al}$ current collector at the positive electrode as, unlike $\mathrm{Li}, \mathrm{Na}$ does not alloy with $\mathrm{Al}$ [9], thus significantly reducing costs associated with the $\mathrm{Cu}$ current collector in Li ion batteries. The use of $\mathrm{Al}$ current collectors at both electrodes also enables the transport of fully discharged Na-ion cells as $\mathrm{Al}$ does not dissolve into the electrolyte at low voltages [10], allowing safer shipping of cells whilst also removing the risk of metal precipitation on the surface of electrodes when charging cells after transportation.

Despite both Li-ion and Na-ion sharing similar mechanisms of operation, i.e. intercalation and de-intercalation of ions from a positive electrode to a negative electrode, the materials 
used in the respective cells can differ substantially [11]. Graphite is the most widely used negative electrode material in Li-ion cells; however, the sodiation of graphite is not thermodynamically favourable $[12,13]$. As such, recent efforts have focussed on obtaining suitable, economically viable negative electrode materials of comparable capacity to the graphite used in Li-ion systems. Hard carbon has, to date, been the most promising material for the negative electrode in Na-ion systems, with a reversible capacity of the order of 280 $300 \mathrm{mAh} \mathrm{g}{ }^{-1}$ being reported $[14,15]$. These electrodes have been reported to suffer from capacity fade over multiple cycles and a poor first cycle Faradaic efficiency [16] to a significantly greater extent than Li-ion cells, although this can be somewhat mitigated through careful design of the electrode [17]. Other carbon-based materials have also generated notable interest [18-20], whilst metal alloy and oxide materials have been reported to have the potential to produce high capacity negative electrodes [21-23]. Although it would be beneficial in terms of capacity to use solid $\mathrm{Na}$ metal as a negative electrode, reports have highlighted issues with dendrite formation on the surface of such an electrode, which has implications for both the lifetime and safety of the cell $[9,24,25]$.

The positive electrode of Na-ion batteries has also seen considerable research with an array of materials similar in structure to those used widely in Li-ion cells reported [11]; however, these materials have been reported to demonstrate lower intercalation/deintercalation rates [9]. Despite this rate limitation, Ong et al. have reported that the diffusion barriers for $\mathrm{Na}^{+}$ ions can be lower than $\mathrm{Li}^{+}$ions in layered $\mathrm{AMO}_{2}$ structures [26] and as such, the most prevalent compounds used in Na-ion positive electrodes are layered transition metal oxides [27-29]. Whilst Ong et al. noted the reduced insertion rate of polyanionic compounds [26], there is still considerable interest in these materials [30]. The capacity retention of $\mathrm{Na}_{3} \mathrm{~V}_{2}\left(\mathrm{PO}_{4}\right)_{3}$ positive electrodes has been reported to be extremely high when supported by 
carbon structures [31]; however, the capacity and rate performance in such electrodes are lower than alternatives. Efforts to reduce the cost and quantity of transition metals in positive electrodes has also seen interest in the development of so-called 'green electrodes' which are based upon organic materials. Whilst there are a range of suitable materials, these organic compounds typically display comparatively poor capacity and rate performance when tested [32-34].

Microstructural studies of Na-ion systems are limited across the literature. Su et al. [35] have examined the microstructural changes associated with the sodiation and desodiation processes in carbon nanotubes in-situ using transmission electron microscopy, enabling the direct measurement of the expansion of nanostructured materials. Wang et al. [36] were the first to report the use of X-ray techniques to probe the sodiation/desodiation process in Na-ion cells. In this work, the authors utilised synchrotron techniques to visualise the expansion of $\mathrm{Sn}$ anodes associated with the insertion of $\mathrm{Na}^{+}$ions over 10 cycles. These results were then compared to the effect of lithiation and delithiation on the same material, showing a significantly larger expansion can be attributed to the sodiation process, with expansions of 326 vol\% reported. It was also highlighted that the size of the Sn particles impacted on the mechanical stability of the anodes, with particles of 5-10 $\mu \mathrm{m}$ showing increased structural changes when compared to those of $\sim 500 \mathrm{~nm}$.

In contrast to Na-ion studies, microstructural techniques have been widely applied to Li-ion systems to elucidate information related to the operation and failure of batteries. Shearing et al. were the first to describe the 3-dimensional microstructure of a Li-ion electrode using Xray computed tomography (CT) [37]. Since this work, X-ray CT has been used to characterise a diverse range of properties and phenomena associated with Li-ion cells, including the failure of pouch cells [38] and the heating effects associated with external 
components of cells [39]. The operando microstructural changes in cells have also been investigated using CT techniques. Eastwood et al. investigated changes induced in the electrodes of a manganese oxide cell due to charge cycling [40], while Finegan et al. [41] examined the strain induced during discharge of a $\mathrm{Li} / \mathrm{MnO}_{2}$ cell using digital volume correlation enabled by X-ray CT. Finegan et al. also demonstrated the failure of commercial 18650 cells in operando due to thermal runaway using synchrotron X-ray radiation [42]; further work performed by the same authors examined the effect of overcharge induced thermal failure on the microstructure of $\mathrm{LiCoO}_{2}$ cells [43].

Studies of the thermal runaway process in such Na-ion cells has recently been reported by the authors [44], showing that the maximum temperature reached by Na-ion cells during thermal runaway is slightly lower than for comparable Li-ion batteries. The thermal stability of materials has also been studied by $\mathrm{Xia}$ and Dahn [45] who found that $\mathrm{NaCrO}_{2}$ is a less reactive positive electrode material than $\mathrm{LiFePO}_{4}$ in non-aqueous electrolyte. It has been suggested that the solid electrolyte interphase (SEI) layer in Na-ion cells may be more soluble than in Li-ion cells, resulting in an earlier onset temperature for self-heating in Na-ion cells. Here, for the first time, to the authors' knowledge, we examine the effect of thermal runaway on the microstructure of a Na-ion cell over a range of length-scales using X-ray computed tomography.

\section{Experimental}

The Na-ion cell used in this work is a pouch cell comprised of a layered oxide, transition metal based cathode material $\left(\mathrm{NaNi}_{1 / 3} \mathrm{Fe}_{1 / 6} \mathrm{Mn}_{1 / 3} \mathrm{Mg}_{1 / 12} \mathrm{Sn}_{1 / 12} \mathrm{O}_{2}\right)$ and hard carbon anode material, with a polypropylene separator, and mixed carbonate solvent (EC:DEC) and 1M $\mathrm{NaPF}_{6}$ salt [46] and a capacity of $3 \mathrm{Ah}$. Prior to conducting the accelerating rate calorimetry 
(ARC) experiments the battery was fully charged to $4 \mathrm{~V}$ (the maximum rated voltage) at $1 \mathrm{C}$, via a constant-current, constant-voltage charging protocol before being allowed to equilibrate at open circuit potential. Fresh samples were prepared using sheets of unformed electrodes similar to those used in the battery. Both fresh electrodes were calendared to mimic the initial conditions of the electrodes in the cell with the fresh cathode being fully sodiated.

Accelerating rate calorimetry was performed inside a calorimeter (Phitec Battery Test Calorimeter, HEL Group, Herts., UK) using the 'heat-wait-search' method. This is a standard method that involves heating the sample to the start temperature, following which a period is observed for the environmental temperature to stabilise followed by the measurement of any self-heating. After thermal runaway, the calorimeter was left to cool to ambient temperature before the electrodes of the cell were harvested [44].

Multi-scale X-ray tomography (CT) was performed using lab-based systems [47, 48]: NanoCT was performed using a Zeiss Xradia Ultra 810 (Carl Zeiss XRM, Pleasanton, CA, USA) on both the fresh and failed electrodes, resulting in an isotropic $63.1 \mathrm{~nm}$ voxel resolution for all samples. To achieve this, small samples (ca. $100 \mu \mathrm{m}$ ) were prepared on pinheads using a technique similar to those described by Heenan et al. [49]. Imaging was then performed using a $\mathrm{Cr}$ target at a fixed accelerating voltage of $35 \mathrm{kV}_{\mathrm{p}}$ with a tube current of $25 \mathrm{~mA}$. For all samples, Zernike phase contrast and absorption images were obtained with exposure times varying depending on the samples' density, as shown in Table 1. These two distinct imaging types enable clearer images to be visualised by combining complimentary techniques; Zernike phase contrast tomography [50], which highlights edge effects between different material phases, and the more common absorption based computed tomography which provides greater contrast between distinct phases with significant difference in attenuation. Micro-CT was performed using a Zeiss Xradia Versa 520 (Carl Zeiss XRM, Pleasanton, CA, USA) which 
resulted in an approximate isotropic $0.71 \mu \mathrm{m}$ voxel resolution. Variations in the actual pixel size which occurred due to the sample alignment procedure were accounted for by binning the reconstructed datasets to the resolution of the largest pixel size, in this instance $0.713 \mu \mathrm{m}$; this allowed for direct comparison of the reconstructed datasets at similar resolutions. The scans were performed using samples harvested from both the fresh and failed cells using a $20 \times$ magnification objective with the imaging conditions used varying depending on the sample examined (see Table 1).

Table 1 Imaging conditions used to obtain the radiographic datasets and the ultimate pixel resolutions used in this work.

\begin{tabular}{|c|c|c|c|c|c|c|}
\hline & & & $\begin{array}{l}\text { Fresh } \\
\text { Anode }\end{array}$ & $\begin{array}{l}\text { Failed } \\
\text { Anode }\end{array}$ & $\begin{array}{c}\text { Fresh } \\
\text { Cathode }\end{array}$ & $\begin{array}{c}\text { Failed } \\
\text { Cathode }\end{array}$ \\
\hline \multirow{4}{*}{$\begin{array}{l}\text { Micro- } \\
\text { CT }\end{array}$} & \multicolumn{2}{|c|}{ Exposure Time (s) } & 15 & 10 & 21 & 25 \\
\hline & \multicolumn{2}{|c|}{ Number of Projections } & 1601 & 1601 & 1201 & 1201 \\
\hline & \multicolumn{2}{|c|}{ Accelerating Voltage $(\mathrm{kV})$} & 60 & 60 & 80 & 80 \\
\hline & \multicolumn{2}{|c|}{ Pixel Size $(\mu \mathrm{m})$} & 0.713 & 0.713 & 0.713 & 0.713 \\
\hline \multirow{5}{*}{$\begin{array}{c}\text { Nano- } \\
\text { CT }\end{array}$} & \multirow{2}{*}{ Exposure Time (s) } & Absorption & 20 & 20 & 35 & 40 \\
\hline & & Phase & 60 & 60 & 60 & 65 \\
\hline & \multirow{2}{*}{$\begin{array}{l}\text { Number of } \\
\text { Projections }\end{array}$} & Absorption & 901 & 901 & 901 & 901 \\
\hline & & Phase & 901 & 901 & 901 & 901 \\
\hline & \multicolumn{2}{|c|}{ Pixel Size (nm) } & 63.1 & 63.1 & 63.1 & 63.1 \\
\hline
\end{tabular}

Reconstruction of the nano- and micro-CT radiographs was performed via parallel- and conebeam filtered-back projection algorithms, respectively, using commercial software ('Reconstructor Scout-and-Scan', Zeiss, Carl Zeiss., CA, U.S.A.) and visualisation was achieved in Avizo Fire software (Avizo, Thermo Fisher Scientific, Waltham, Massachusetts, U.S.). Measurements of the samples' porosity and surface area were performed using TauFactor, an open-source MATLAB application for porous material analysis [51]. Analysis of the cathode composition was performed using energy dispersive X-ray spectroscopy (EDX). The fresh and failed samples were initially imaged using a Zeiss EVO 10 (Carl Zeiss AG, Germany) scanning electron microscope to identify suitable regions to examine. EDX was subsequently performed using 
an AztecONE detector (Oxford Instruments, Oxford, UK) with an accelerating voltage of 15 $\mathrm{kV}$ used to image the samples and energies ranging from $0-20 \mathrm{keV}$ measured. Analysis of the results was performed using INCA software (Oxford Instruments, Oxford, UK) with the oxygen peak identified at approximately $0.5 \mathrm{keV}$.

\section{Results and Discussion}

Thermal runaway has previously been shown to cause significant morphological changes to electrode structures in Li-ion batteries [43]; however, previous work [44] has shown that thermal runaway is a less exothermic event in comparable Na-ion cells. The temperature profile obtained as a result of thermal runaway can be seen in Figure 1, with the maximum temperature observed being limited to $280{ }^{\circ} \mathrm{C}$ as a result of hardware limitations, as demonstrated in previous work [52]. When the cell was removed, it was observed that the side of the pouch had ruptured during thermal runaway and that the cathode material had partially delaminated from the aluminium current collector. In contrast, the failed anode

remained coated on the current collector, although the layer was more brittle than a comparable fresh electrode. Additionally, no melting of the Al current collector was observed. Thus, it was inferred that the maximum temperature reached during thermal runaway must be less than $660^{\circ} \mathrm{C}$ (the melting point of aluminium). 


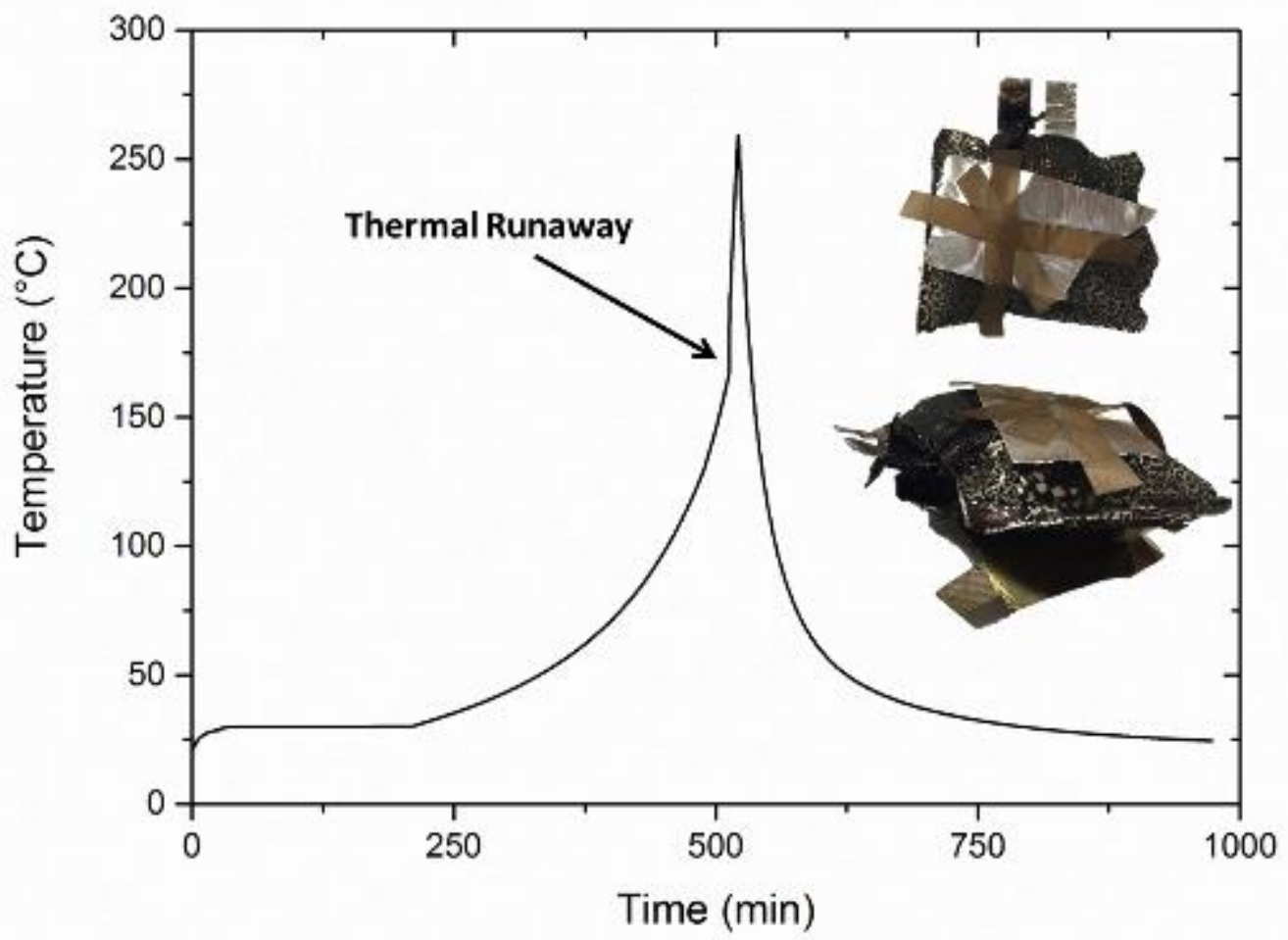

Figure 1 Temperature profiling showing the onset and propagation of thermal runaway in a Na-ion cell induced by accelerating rate calorimetry. Images of the remnants of the cell are inlaid, highlighting the complete failure of the cell.

Samples of both the failed anode and cathode were harvested by isolating each layer from the failed cell. The compositions of the different layers were identified by scanning electron microscopy and energy dispersive spectroscopy with the individual samples prepared as described previously. Sheets of anode and cathode printed electrodes, similar to those used in the failed cell, were used to prepare the fresh samples for the X-ray characterisation. These fresh electrodes were stored in a glovebox to ensure they were not exposed to the atmosphere prior to analysis, which may result in the degradation of the material. The failed cells were not stored in an inert environment as they were exposed to the atmosphere as a result of thermal runaway. Orthogonal slices from the reconstructed X-ray CT datasets are shown for each of the electrodes in Figure 2. 

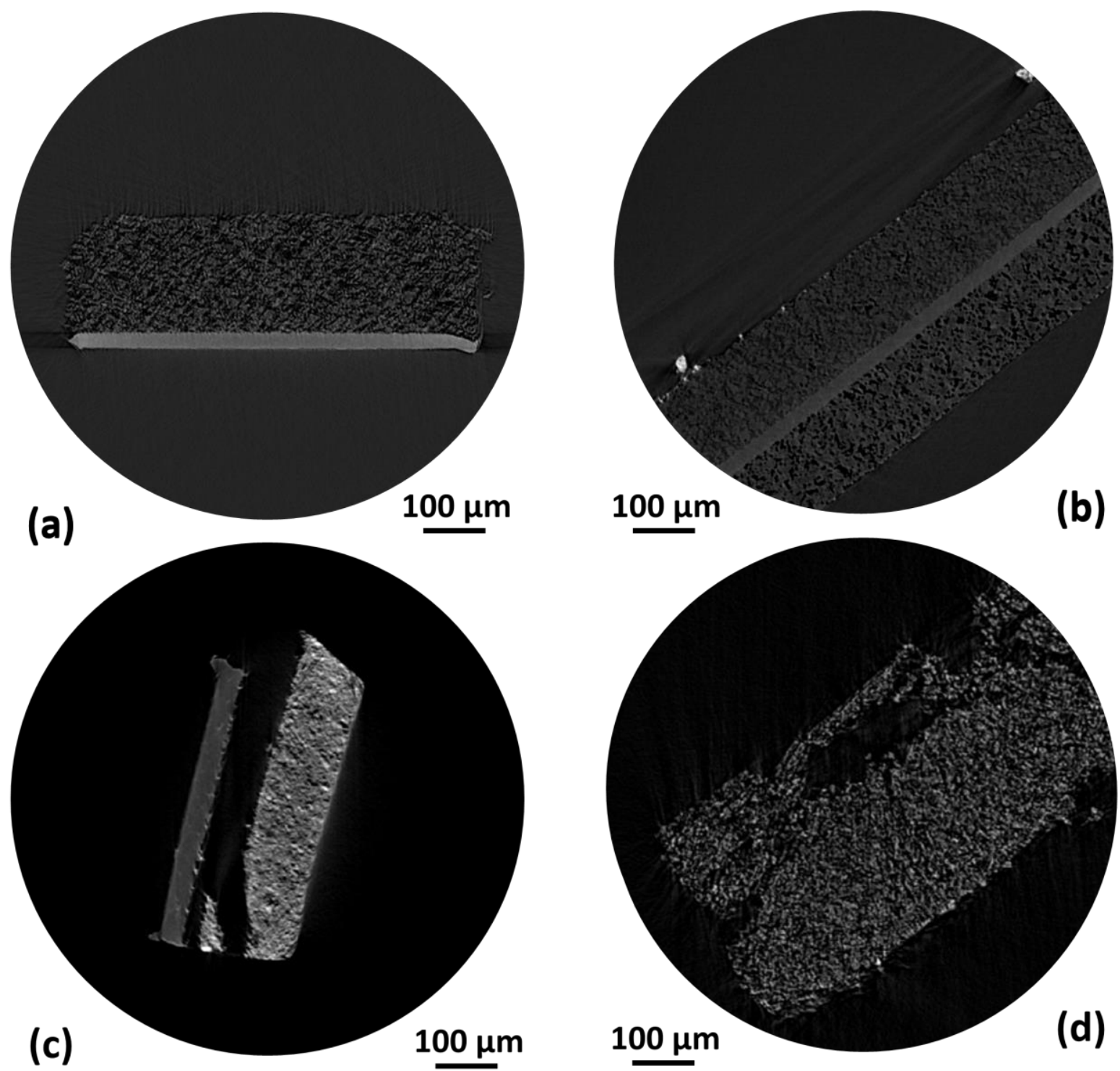

Figure 2 Orthogonal slices showing the reconstructed (a) fresh anode, (b) failed anode, (c) fresh cathode and (d) failed cathode obtained using a Versa 520 with an isotropic pixel size of $0.713 \mu \mathrm{m}$.

Analysis of the orthogonal slices shown in Figure 2 show that the thickness of the failed anode was approximately $20 \%$ smaller than the fresh samples. Whilst both anodes had been calendared to the same thickness originally it is possible that some of this contraction was caused by the formation and charging of the cell and the formation of the solid electrolyte interphase (Hong et al. Biomass derived hard carbon). It is also possible that the removal of 
the binder; which will be burned off due to the elevated temperatures associated with failure enabled the anode particles to lie closer to each other resulting in the contraction.

Reconstructed volumes from CT experiments of fresh and failed samples of the anode material are shown in Figure 3. It can be observed that after failure, deposits of material are present on the surface of the electrode; these can also be seen as white, highly attenuating layers in Figure 2(b). This highly attenuating material deposition, occurred as a result of the thermal runaway reactions. This phase has a significantly larger X-ray attenuation (ca. 160 $\%)$ than both the hard carbon and aluminium which comprised the electrode prior to failure, and as such is inferred to be metallic as a result of this higher attenuation value. The layer is believed to exist as a result of the melting of the separator due to thermal runaway. As a result of the high temperatures and pressures in the cell caused by the failure the electrodes are believed to have contacted each other enabling a material to be transferred from each other and resulting in the deposition of a small amount of the cathode material on the surface of the anode. Figure $3(\mathrm{c}, \mathrm{d})$ also shows a qualitative decrease in porosity of the anode layer after the failure of the cell. This decrease in porosity is in corresponds to the previously observed reduction in thickness of the anode and is likely due to a number of factors as discussed; it is however, not possible, to identify an exact cause at this resolution. 


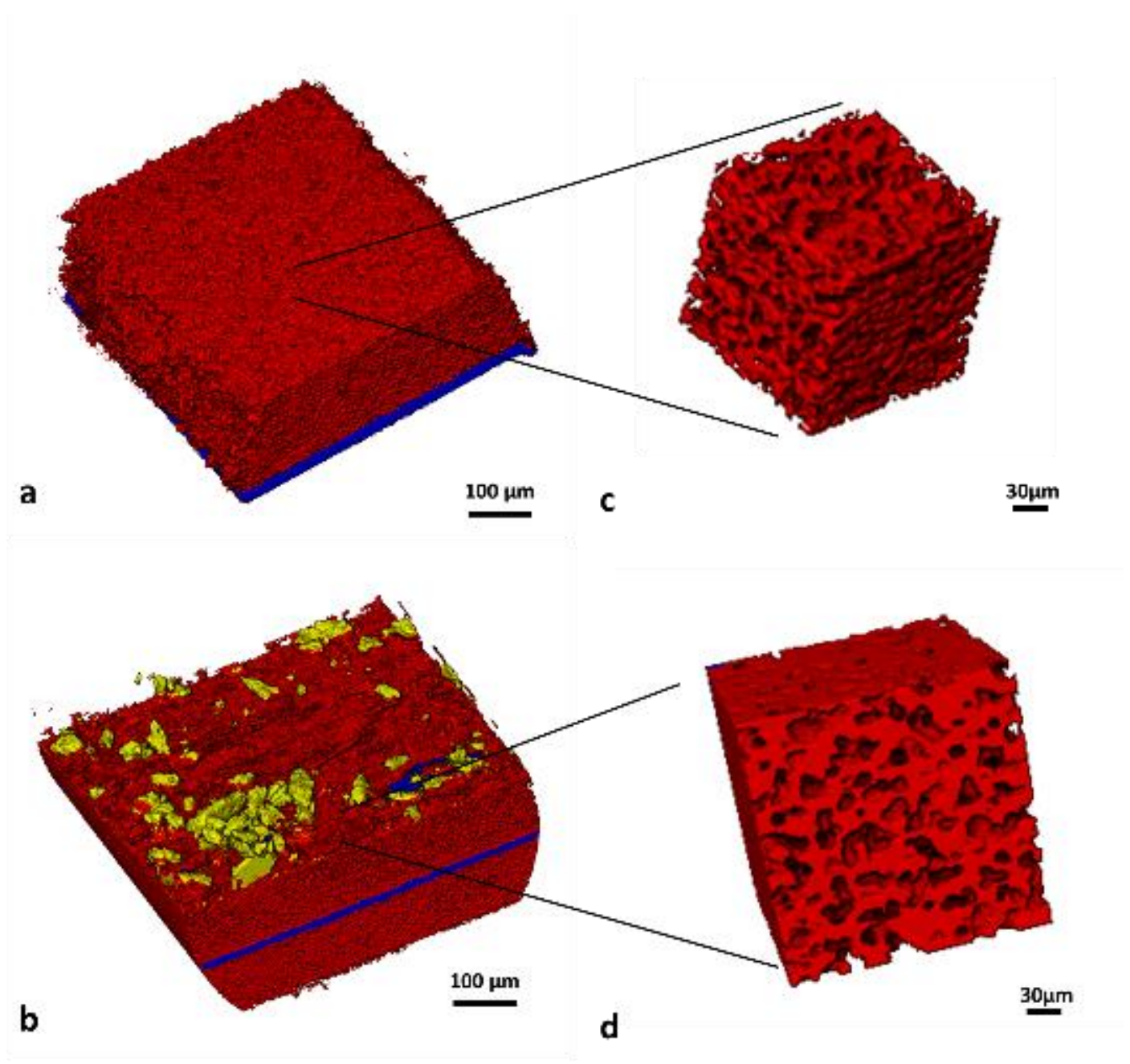

Figure 3 Three-dimensional microstructural reconstructions of the anode showing the fresh bulk (a) and failed bulk (b) with an expanded view of the fresh anode (c) and failed anode (d) of the Na-ion cell as obtained using a Zeiss Versa 520 with voxel resolutions of $0.713 \mu \mathrm{m}$.

The fresh cathode layer used in the Na-ion cell [shown in Figure $2(\mathrm{c}, \mathrm{d})$ ] were seen to be more brittle than the fresh anode layer, which resulted in a number of macrostructural cracks in the electrode formed in the sample preparation process, visible in Figure 4(a). In contrast to the anode, no particles of higher attenuation were observed on the surface of the cathode after failure; however, it was observed that the porosity of the electrode increased notably after thermal runaway; this is visible in the expanded volumes shown in Figure 4(b, d). Similar increases in cathode porosity have been observed in Li-ion batteries during thermal runaway as a result of the interaction between the electrolyte and cathode material, which has 
been reported to cause the failure of such cells [53]. These interactions have been reported to result in the generation of a range of hydrocarbon gases which pass through the material, increasing the porosity $[43,54]$.
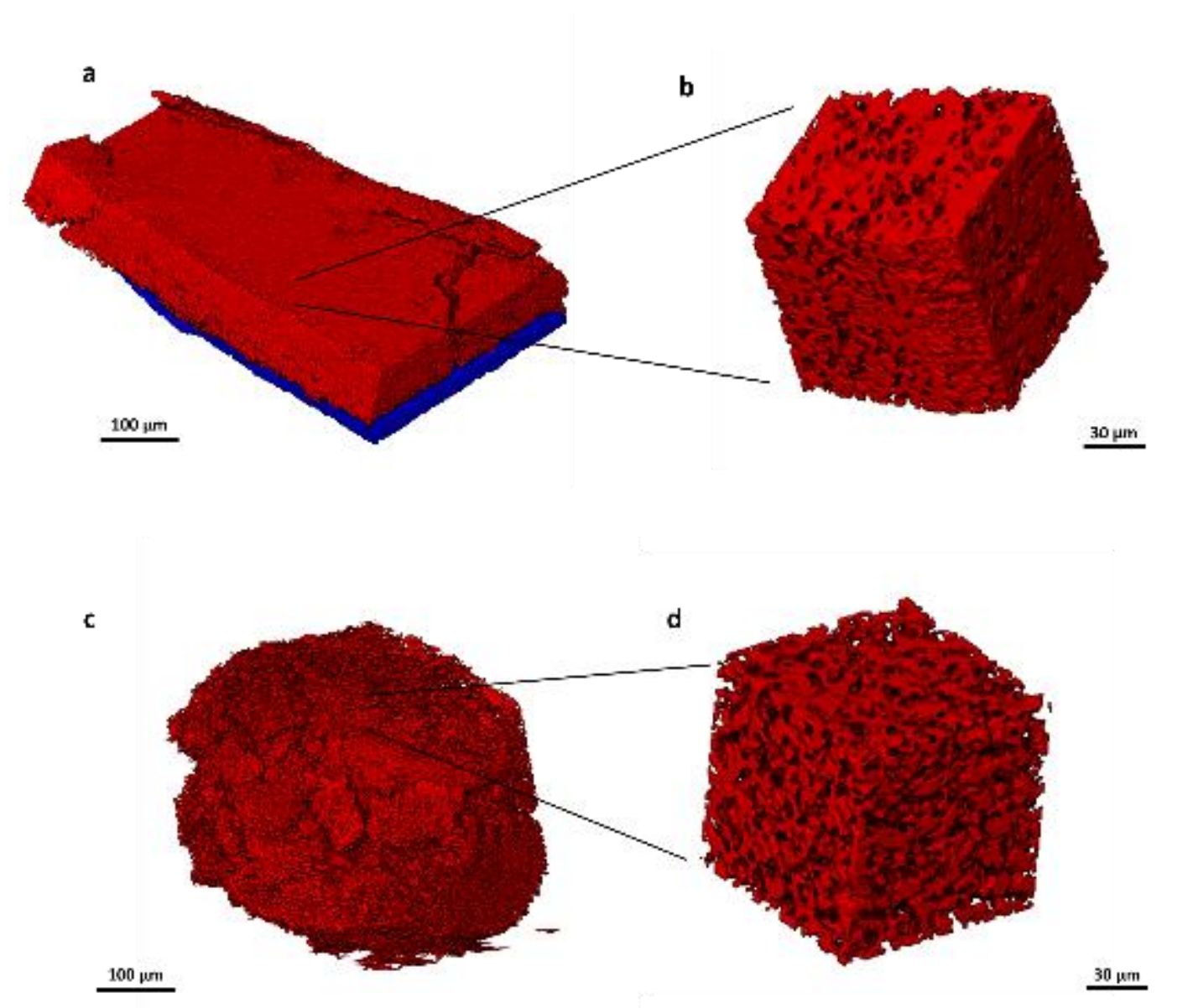

Figure 4 Three-dimensional reconstructions of the Na-ion cell microstructure as obtained using a Zeiss Versa 520 with isotropic voxel resolutions of $0.713 \mu \mathrm{m}$ : the (a) bulk and (b) expanded view of the fresh cathode and the (c) bulk and (d) expanded view of the failed cathode.

In order to quantify the extent of the changes in the bulk microstructure, porosity measurements were performed using TauFactor [51]. To ensure external regions were not considered, cuboid sub-volumes of all electrodes were generated to conduct the analysis. Representative volume element analysis was performed by analysing two regions of different sizes and locations and comparing the findings in TauFactor to ensure localise 
inhomogeneities did not adversely affect the results. In all instances deviations in the results of less than $3 \%$ were observed, indicating the volumes analysed were sufficiently large as to accurately represent the bulk electrodes [55]. The volume specific surface area (VSSA) was also calculated and is shown in Table 2 .

Table 2 Microstructural quantification of both fresh and failed electrodes as obtained from a Versa dataset with a voxel resolution of $0.713 \mu \mathrm{m}$.

\begin{tabular}{|c|c|c|c|c|}
\hline & Anode & Cathode & Anode & Cathode \\
\hline Electrode State & \multicolumn{2}{|c|}{ Porosity $(\%)$} & \multicolumn{2}{c|}{ Volume Specific Surface Area $\left(\mu \mathrm{m}^{2} \mu^{-3}\right)$} \\
\hline Fresh & 47.3 & 30.7 & 529 & 519 \\
\hline Failed & 18.6 & 43.1 & 217 & 501 \\
\hline
\end{tabular}

The results of the TauFactor simulation confirm the qualitative observations that porosity changes occurred in both electrodes during the failure process. The changes in porosity in the anode indicate a general contraction of the microstructure, as seen qualitatively in Figure 2 andFigure 3 . Table 2 also shows an increase in porosity of approximately $40 \%$ in the cathode which is suggested to be as a result of the reduction of the metal oxides and subsequent gas generation. This increase in porosity is seen to occur with a reduction in the surface area of the cathode at this length scale indicating that the material in the cathode undergoes a degree of densification as a result of thermal runaway. Whilst it is not possible to ascertain the exact changes in the particle morphology at this resolution it would be expected that an increase in porosity should result in an increased surface area in the electrode.

To quantify the changes in the particle morphology, nano-CT was conducted on samples of the electrodes. Images of the fresh and failed anode material are shown in Figure 5, which show combined Zernike phase contrast and absorption images in order to improve the image quality [56]. By imaging the same sample using both methods the respective datasets can be combined with higher weighting given to either of the techniques to provide the clearest image. In this instance the absorption image was combined with the Zernike phase contrast 
image with a weighting of 25:75 in order to provide enhancement to the edges of the carbon particles and produce a higher quality image.
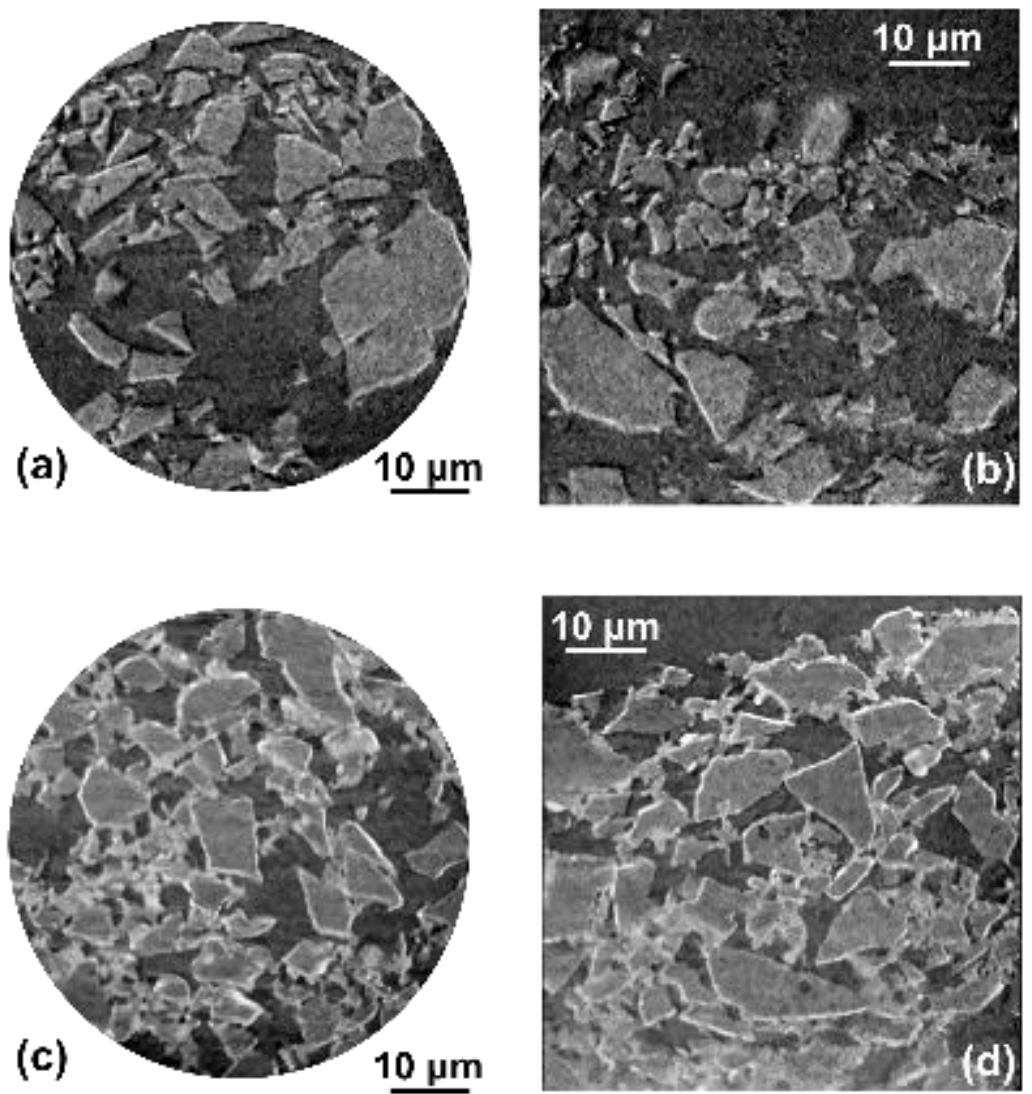

Figure 5 Nano-CT orthogonal slice of reconstructed X-ray datasets showing the (a, b) pristine anode and (c, d) the failed anode with a non-local means filter applied to remove noise. The images shown are combined contrast composites of both absorption and Zernike phase contrast images in order to aid visualisation.

The orthogonal slices displayed in Figure 5 show that despite the violent failure of the cell, the anode particle morphology remains largely similar in both shape and size. The hard carbon anode used in this cell is formed in pyrolysis reactions which occur at temperatures in excess of $1000{ }^{\circ} \mathrm{C}$ [57] and therefore should be unaffected by a thermal runaway event which is believed not exceed $660{ }^{\circ} \mathrm{C}$. The reduction in the anode thickness and porosity shown previously can also be seen in Figure 5 with the inter-particle distance being significantly reduced in the failed electrode. It is suggested that this is a combination of effects caused by 
an initial contraction associated with the formation and charging steps and also the loss of the binder phase during thermal runaway.

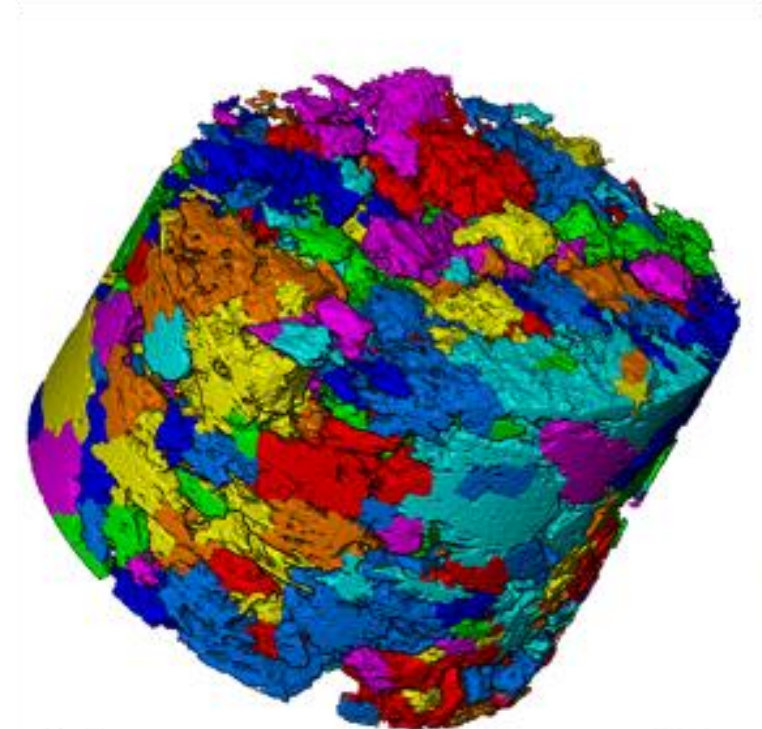

(a)

$10 \mu \mathrm{m}$

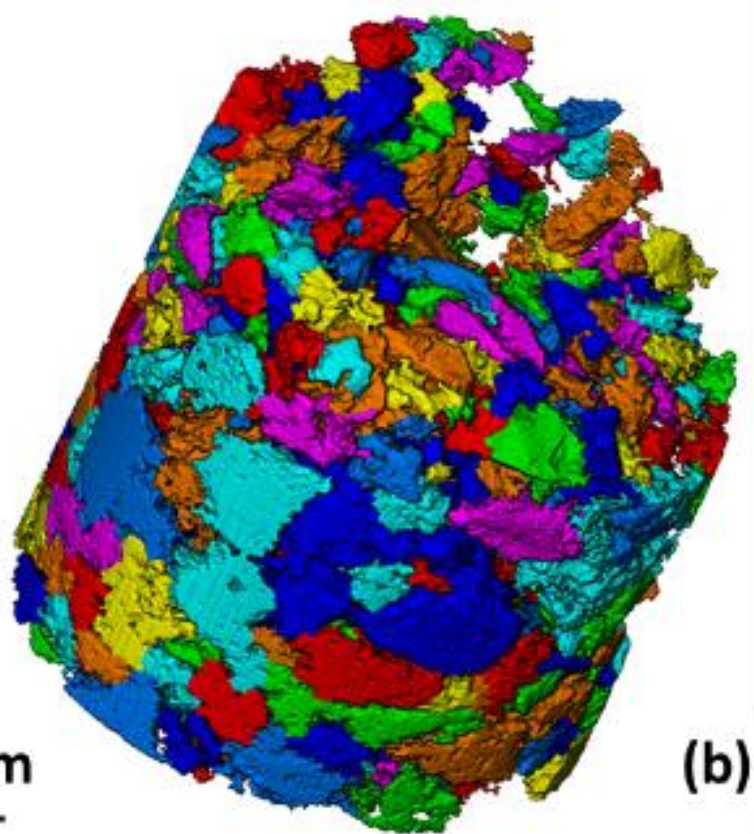

(b)

Figure 6 Volume renderings of the individual particles (with each particle assigned a different colour to the neighbouring particle) within the (a) fresh and (b) failed anode of the Na-ion cell showing comparable particle sizes throughout the sample before and after failure.

The three-dimensional volumes shown in Figure 5 highlight the similarity of both the fresh and failed microstructures through the depth of the samples. Once more, the particle morphologies observed in both the fresh and failed anode are similar. In order to quantify the changes in the particle morphology a particle volume distribution was performed using the label analysis tool in Avizo Fire as shown in Figure 7. To increase the accuracy of these calculations any particle which was not wholly contained within the volume scanned was discounted. Additionally any particle which was calculated to be less than $1 \mu \mathrm{m}^{3}$ was discounted so as to exclude potential errors associated with noise in the data. 


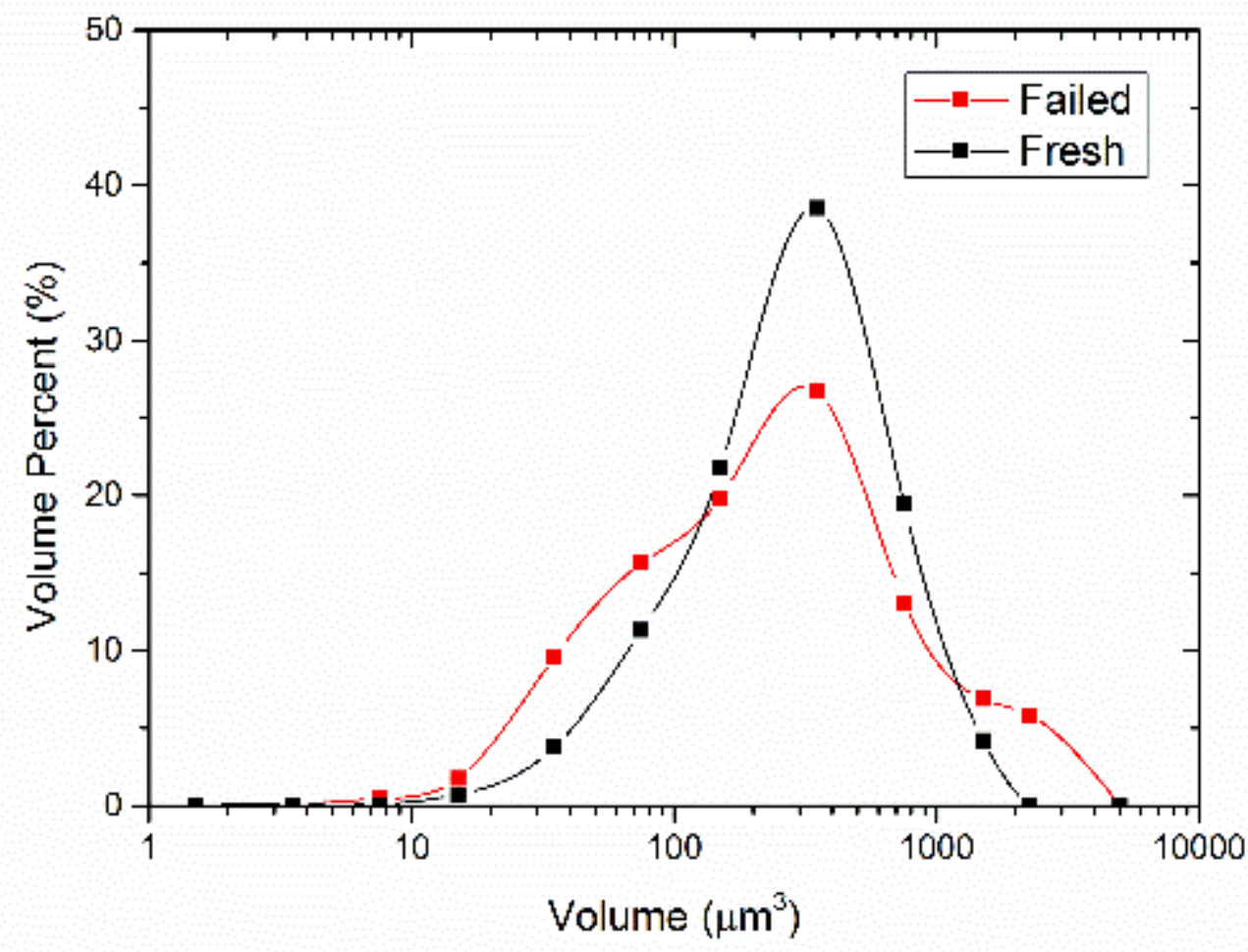

Figure 7 Particle volume distribution of the fresh (black) and failed (red) anode material obtained using a Zeiss Xradia ultra with $63.1 \mathrm{~nm}$ resolution showing a general broadening of the distribution as a result of thermal failure of the battery. In total 398 individual fresh particles and 353 failed particles were analysed to compile the distribution.

The general broadening of the distribution towards lower volumes after failure is consistent with small amounts of fracturing of the anode occurring as a result of the volatile environment within the cell during failure. It can also be seen that there is a number of larger particles observed in the failed anode; this is unlikely to be as a result of the fusion of carbon particles and is, rather, more likely to be a result of a small number of large particles being present in the sample analysed which skew the distribution in the failed cell. The results shown in Figure 7 suggest that whilst on a micro-scale the bulk anode shows some changes as a result of thermal runaway; namely a contraction in the electrode and a corresponding loss of 
porosity, the particle morphology remains largely unchanged. Furthermore, this suggests that the anode material does not partake in the reactions which occur during thermal runaway.

Similar analyses were performed on the cathode in both a fresh and failed state; however, in this instance, large differences were observed in both the particle morphology and the sample condition, as seen in Figure 8.
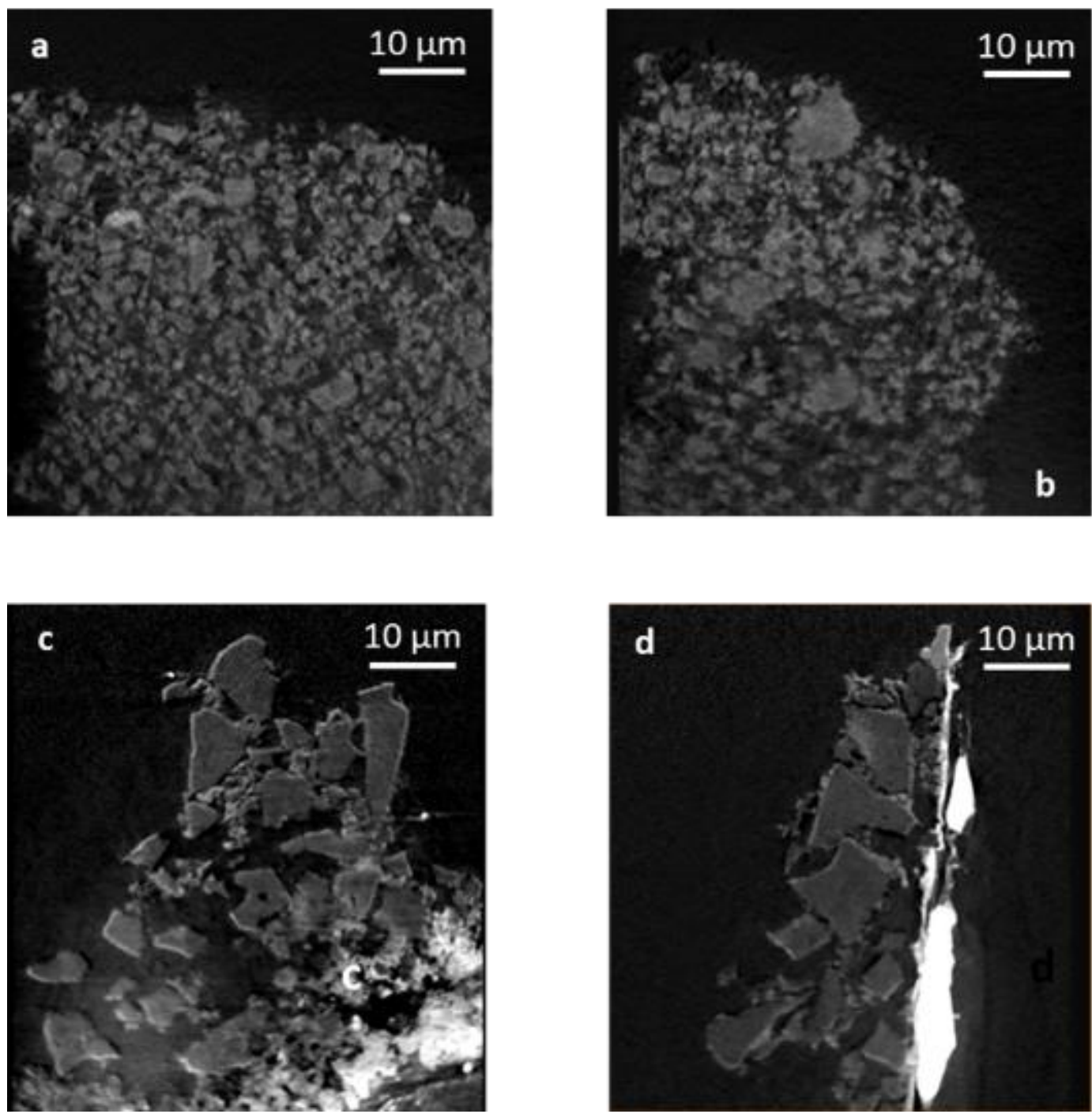

Figure 8 Orthogonal slices of the absorption image of the fresh $(a, b)$ and failed $(c, d)$ cathode highlighting a highly attenuating phase (white) in the failed cathode. Large particles of similar morphology to those seen in Figure 5 can be seen toward the left-hand side of the orthogonal slices shown in (c, d) suggesting that hard carbon particles are adhered to the failed cathode as a result of thermal runaway 
The fresh cathode can be seen to be formed of a complex assembly of relatively small particles in addition to a number of larger particles which are well dispersed throughout the electrode sample. In stark contrast, the failed cathode is seen to consist of a number of large, highly attenuating particles; which, due to their significantly higher grayscale values, are proposed to be a metallic layer; formed due to the reduction of the metal oxide cathode during failure. The large changes in particle size are clearly seen in Figure 9 which highlights the individual particles comprising the respective electrodes.

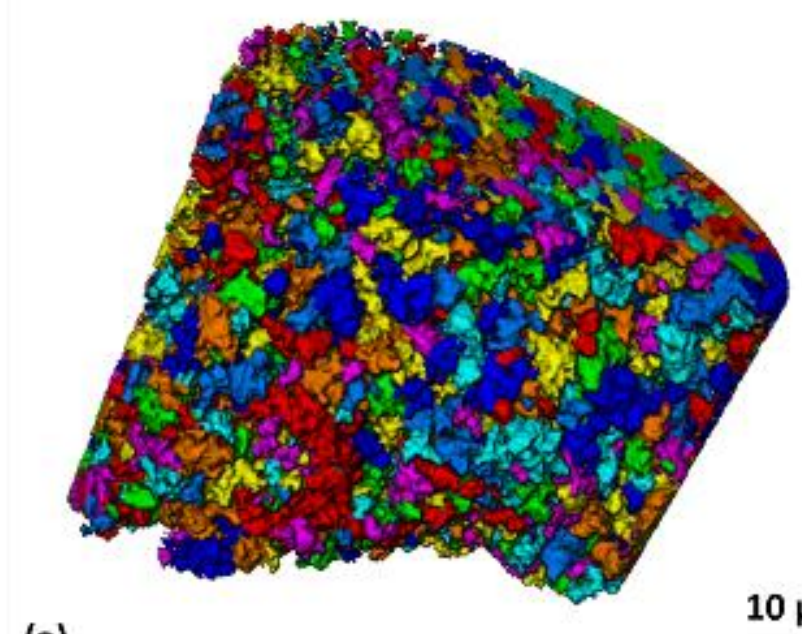

$10 \mu \mathrm{m}$

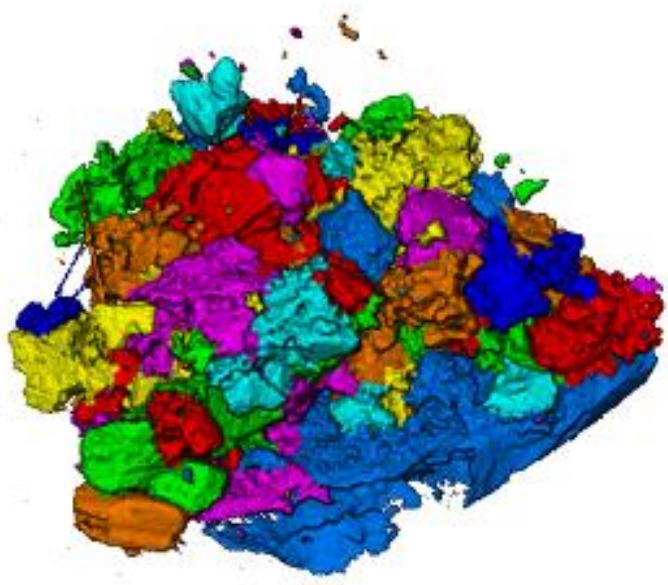

(a)

(b)

Figure 9 Volume renderings of the individual particles (with each particle assigned a different colour to the neighbouring particle) within the (a) fresh and (b) failed cathode of the Na-ion cell showing significant densification of the cathode particles as a result of thermal runaway.

The densification of the cathode post failure, suggested by the findings in Table 2, is consistent with the results observed in the smaller sample when analysed at nanoscale resolution shown in Figure 9. It is evident that a substantial decrease in the porosity between the particles occurs due to the failure of the cell; however, it is also suggested that a change in the composition of the particles occurs as a result of the failure of the cell. While the 
greyscale values of the fresh sample are homogenous throughout both orthogonal slices shown in Figure $8(a, b)$, variations of the attenuation are visible throughout the sample in the failed electrode Figure 8(c, d). Analysis of the change in particle morphology as a result of thermal runaway was performed using similar methods to those described for the anode and are shown in Figure 10.

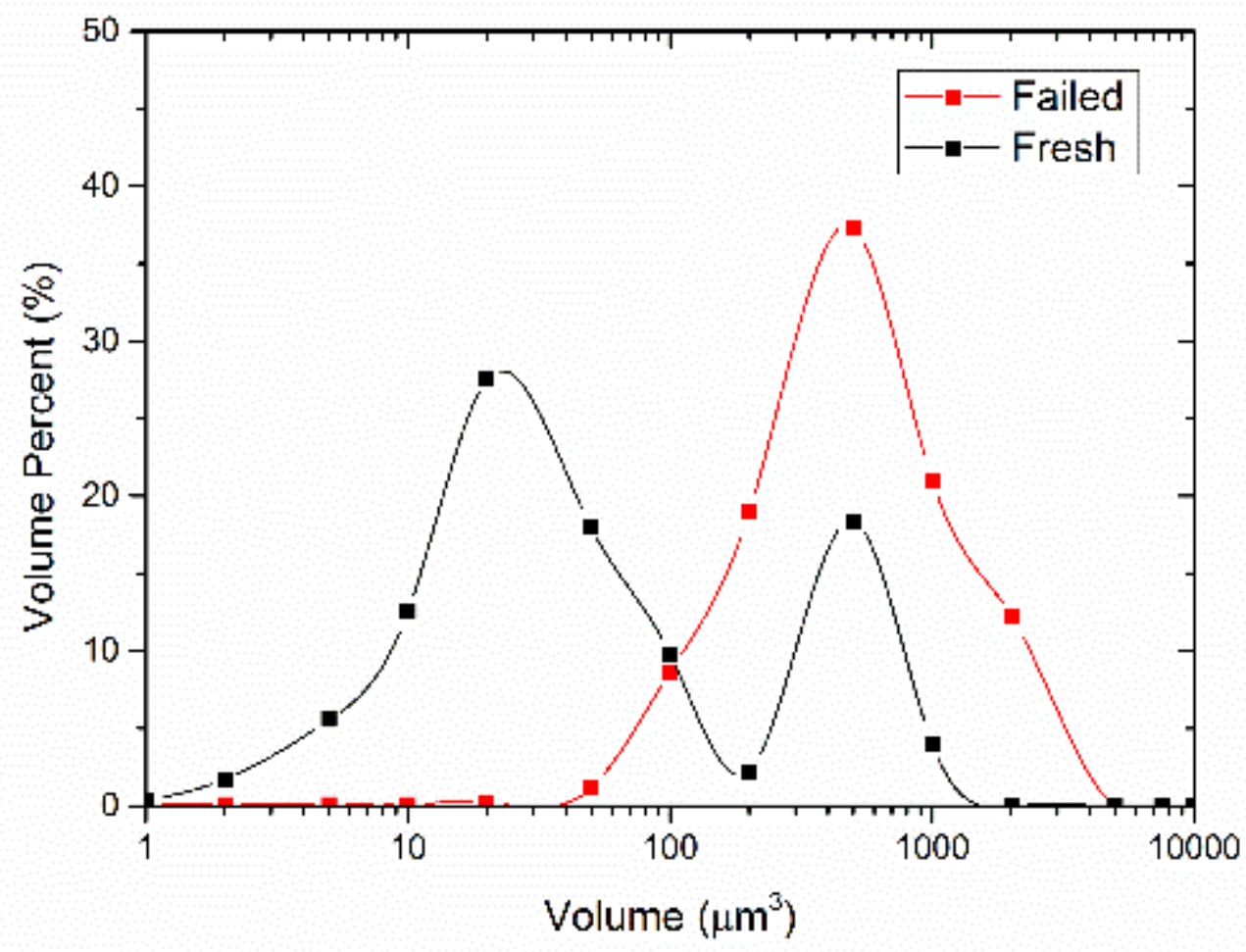

Figure 10 Particle volume distribution of the fresh (black) and failed (red) cathode particles obtained at a $63.1 \mathrm{~nm}$ resolution. In total 2241 particles were analysed for the fresh distribution and 117 particles were analysed for the failed distribution.

In contrast to the anode, a notable change in the distribution is visible between the fresh and failed cathode samples. While the initial distribution is seen to consist of two well defined distributions the failure of the cell can be seen to significantly reduce the number of small particles. These small metal oxide particles are suggested to have reacted with the electrolyte 
with the remaining metals coalescing to form the large particles, visible both in the distribution and in the dense white regions seen in Figure 8. The densification of the electrode observed at the microscale (Table 2) is mirrored in the changes in the mean volumes and surface areas of the distribution as shown in Table 3.

Table 3 Particle analysis of the fresh and failed cathode obtained from a Zeiss Xradia Ultra with a resolution of $63.1 \mathrm{~nm}$.

\begin{tabular}{|c|c|c|c|}
\hline & $\begin{array}{c}\text { Mean Volume } \\
\left(\mu \mathrm{m}^{3}\right)\end{array}$ & $\begin{array}{c}\text { Mean Surface Area } \\
\left(\mu \mathrm{m}^{2}\right)\end{array}$ & Number of Particles \\
\hline Fresh Cathode & 21.68 & 82.12 & 2241 \\
\hline Failed Cathode & 250.73 & 449.92 & 117 \\
\hline
\end{tabular}

While the evident volume change of the particles as seen in Figure 9 and Table 3 suggests a coagulation of the particles in the electrode, it is the large change in the surface area measured at the nano-scale which highlights the densification of the cathode as a result of the reduction of the metal oxides which form the electrode in its fresh state. This densification is in agreement with the results obtained at the micro-scale (as seen in Table 2) which sees a reduction in surface area with an increase in porosity. It can be seen from Table 3 that the ration of surface area to volume is substantially decreased in the failed cells. The total number of particles also suggests that the small particles which comprise the electrodes prior to failure coagulate during failure as a result of reactions between the positive electrode and electrolyte which cause the reduction of the metal oxides. It is also very likely that there is material loss as a result of these reactions which result in the generation of gas and the increased porosity seen in the bulk microstructure observed at the micro-scale (Table 2).

The large highly attenuating particles which appear in the failed cathode [seen in white in Figure $8(\mathrm{c}, \mathrm{d})$ ] are suggested to be a metallic phase formed due to the reduction of the 
cathode material during thermal runaway. To confirm this fresh and failed samples were analysed using energy dispersive X-ray spectroscopy with the results shown in Figure 11. 


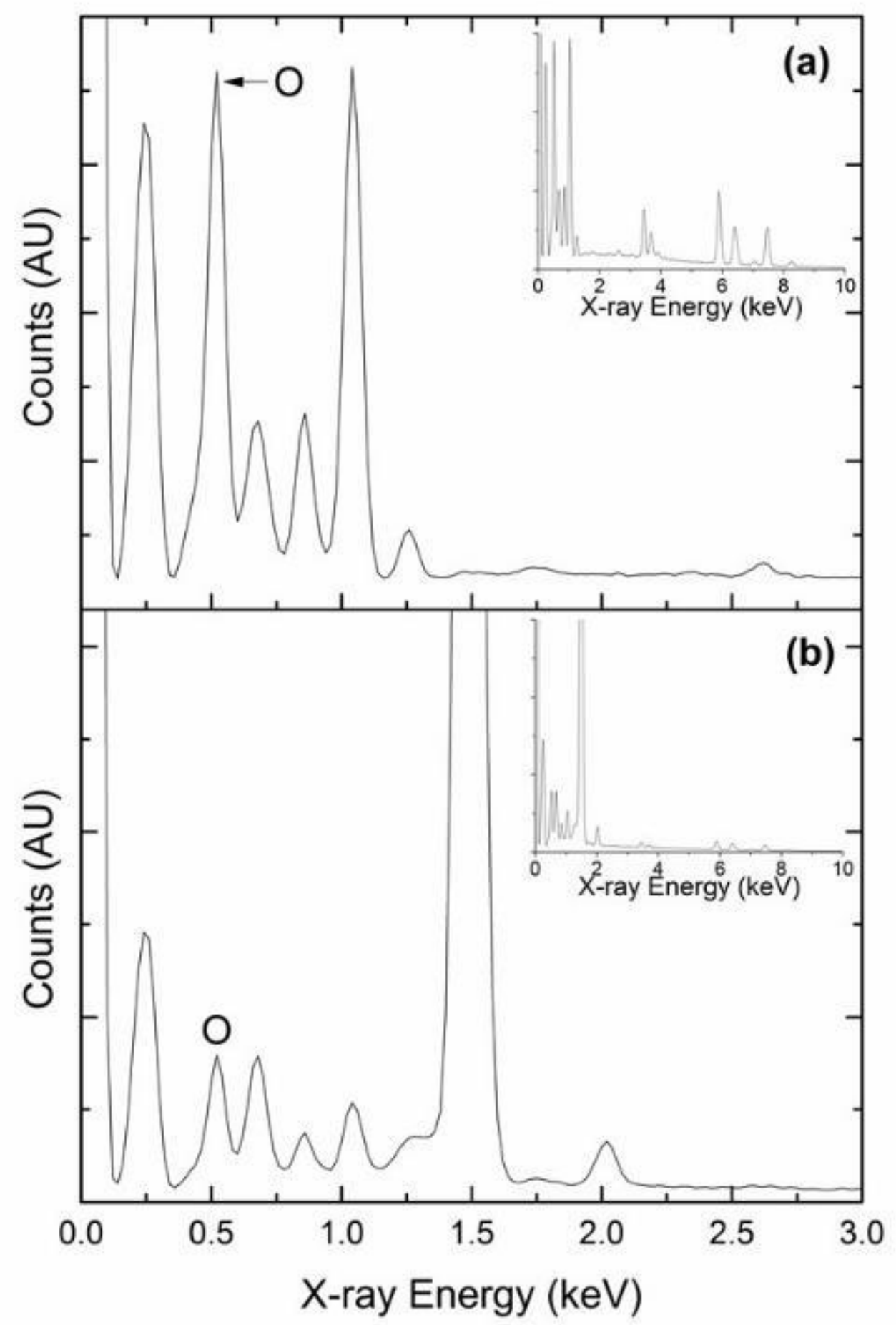

Figure $11 \mathrm{EDX}$ spectra to $3.0 \mathrm{keV}$ of the fresh (a) and failed (b) Na-ion cathode showing a significant reduction in the atomic $O$ peak (labelled) indicating a reduction of the metal oxide based cathode as a result of thermal runaway. The full spectra are inlayed in the respective fresh and failed plots. 
It is clear from Figure 11 that a substantial change in the measured signal occurs as a result of thermal runaway. In particular a large decrease in the oxygen peak suggests that the metal oxides $[46,58]$ which form the active material of the cathode are reduced during thermal runaway. The smaller oxide peak suggests that the highly attenuating regions observed in the orthogonal slices are indeed metallic components formed due to the reduction of metal oxides. Changes in other peaks indicate a reduction of the metal oxide to base metals and an exposure of the aluminium current collector due to the noted decrease in adhesion of the electrode material after the failure of the cell. Similar findings have been reported for electrodes composed of $\mathrm{LiCoO}_{2}$ [43]. One further noticeable difference between the fresh and failed cathode is the appearance of hard carbon particles (shown in blue in Figure 12) post failure. It is suggested that these particles (shown in blue in Figure 12) adhere to the cathode when the electrodes come into contact after the separator has been destroyed during thermal failure.
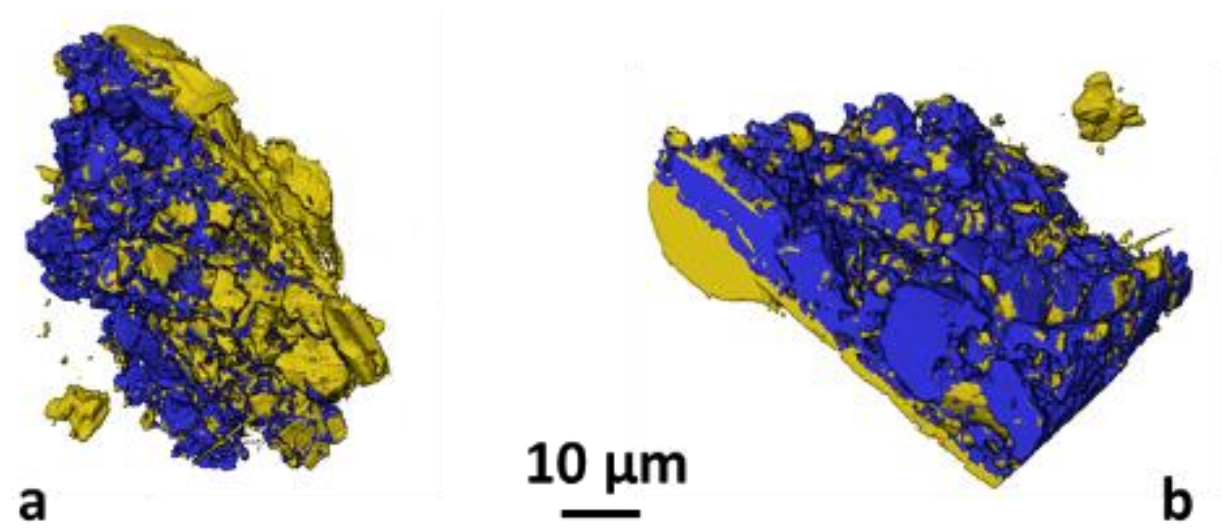

Figure 12 Volume renderings of the failed cathode highlighting the dense metallic layer (gold) and the hard carbon (blue) which adheres to the cathode during failure of the cell.

The volume renderings in Figure 12 show the extent of the disintegration of the electrode structure of the cathode as a result of the thermal failure. Previous work has shown that 
during thermal runaway the $\mathrm{LiCoO}_{2}$ particles in positive electrodes form large internal cracks as a result of the failure $[43,59]$. In contrast, the particles in this work (shown in Figure 8a) are observed to coalesce and form large metallic deposits (shown in gold in Figure 12) resulting in an entirely different electrode structure. The metallic layer (shown in gold in Figure 12) can be seen to percolate through the carbon particles creating a mixed material structure formed from the remnants of the cathode. It is proposed that the reduction of the cathode which results in this densification occurs as a result of thermal failure to the interaction between the cathode and electrolyte at elevated temperatures via reaction mechanisms similar to those reported for Li-ion cells [53].

The contrast in the morphological behaviours of the electrodes in this work suggest that $\overline{\bar{y}_{2}}$ in a similar process to Li-ion batteries, thermal runaway in Na-ion cells causes a significant degradation of the cathode, suggesting the mechanism of thermal runaway is likely largely due to the reaction of the cathode and electrolyte, in a similar manner to Li-ion cells. Previous work has shown that the thermal runaway process in Na-ion systems is less rapid than in Li-ion cells [44]. The substantial reduction of the cathode as shown via EDX in this work may suggest that this reduced rate is inherent to the materials rather than as a result of a variation in the pathways of thermal runaway or the microstructural behaviour of the positive electrode.

\section{Conclusions}

The microstructural effects of thermal runaway induced via accelerating rate calorimetry has shown that changes occur in both electrodes at different length scales as a result of the failure process. Examination of fresh and failed electrode material has shown that thermal runaway results in bulk changes in porosity of both electrodes; in the case of the anode, a reduced 
porosity can be explained by a compression of the electrode associated with the formation step and a potential contraction due to the loss of the binding phase. An increased porosity in the bulk cathode as result of thermal runaway is consistent with results reported for $\mathrm{Li}$-ion systems and suggests that thermal runaway occurs via similar reaction mechanisms in Na-ion systems.

Analysis of the anode suggested that despite the significant contraction in the electrode the particle morphology remained unchanged on the nanoscale. The size and shape of the anode particles was seen to be largely unchanged in the anode post failure suggesting the electrode is benign in the thermal runaway reaction. This implies the contraction in the thickness of the bulk microstructure most likely as a result of the violent conditions which occur inside the cell during failure rather than any chemical effect.

In contrast, while the porosity of the cathode increased as a result of failure the solid surface area density decreased suggesting a bulk densification of the electrode material at the microscale. This was confirmed by analysis of the electrode at the nanoscale. Coalescence and a composition change of the cathode particles were observed with hard carbon particles passing from the anode to the cathode during thermal failure once the separator melts. It was observed that the cathode was almost completely destroyed during failure, with a significant reduction in the oxygen peak suggesting that this may be as a result of the reduction of the metal oxide components in the cathode to base metals. Furthermore, this finding suggests that rather than the lower rate of thermal runaway previously reported in $\mathrm{Na}$-ion batteries may be inherent to the materials used. While the thermal effects of safety are not the only important factor to consider when analysing battery safety it is apparent that this reduced reaction rate could have implications for the safer construction of battery packs and reduced costs associated with safety systems in large battery systems. 


\section{Acknowledgements}

The authors would like to acknowledge the EPSRC funding for supporting the work of Robinson through the UCL Doctoral Prize Fellowship (EP/M507970/1) scheme and the EPSRC for supporting the energy storage work in the Electrochemical Innovation Lab (EP/N032888/1; EP/N001583/1. EP/P009050/1; EP/M009394/1). The authors also acknowledge the STFC for supporting Shearing and Brett (ST/K00171X/1) and Royal Academy of Engineering for supporting Robinson (ICRF1718\1\34) and Shearing. The authors would like to thank Sharp Laboratories of Europ Ltd. for the prototype Na-ion cells.

\section{References}

[1] G.P. Beauregard, in, U.S. Department of Energy, Idaho National Laboratory, 2008.

[2] JTSB, Aircraft serious incident investigation report, All Nippon Airways Co., LTD JA804A

[3] AAIB, Report $n n$ the serious incident to Boeing B787-8, ET-AOP London Heathrow Airport on 12 July 2013.

[4] NTSB, Interim Factual Report DCA13IA037, Boston, 2013.

[5] B.L. Ellis, W.R.M. Makahnouk, W.N. Rowan-Weetaluktuk, D.H. Ryan, L.F. Nazar, Chemistry of Materials, 22 (2010) 1059-1070.

[6] United States Geological Survey, Mineral Commodity Summaries, 2009

[7] V. Palomares, P. Serras, I. Villaluenga, K.B. Hueso, J. Carretero-Gonzalez, T. Rojo, Energy \& Environmental Science, 5 (2012) 5884-5901.

[8] K. Vignarooban, R. Kushagra, A. Elango, P. Badami, B.E. Mellander, X. Xu, T.G. Tucker, C. Nam, A.M. Kannan, International Journal of Hydrogen Energy, 41 (2016) 28292846.

[9] M.D. Slater, D. Kim, E. Lee, C.S. Johnson, Advanced Functional Materials, 23 (2013) 947-958.

[10] J. Barker, C.J. Wright, Patent No. WO2016027082A1, 2016.

[11] S.-W. Kim, D.-H. Seo, X. Ma, G. Ceder, K. Kang, Advanced Energy Materials, 2 (2012) 710-721. 
[12] C. Bommier, W. Luo, W.-Y. Gao, A. Greaney, S. Ma, X. Ji, Carbon, 76 (2014) 165-174.

[13] D.A. Stevens, J.R. Dahn, Journal of The Electrochemical Society, 148 (2001) A803A811.

[14] P. Thomas, D. Billaud, Electrochimica Acta, 47 (2002) 3303-3307.

[15] D.A. Stevens, J.R. Dahn, Journal of The Electrochemical Society, 147 (2000) 1271 1273 .

[16] K. Kubota, S. Komaba, Journal of The Electrochemical Society, 162 (2015) A2538A2550.

[17] V.L. Chevrier, G. Ceder, Journal of The Electrochemical Society, 158 (2011) A1011A1014.

[18] R. Alcántara, P. Lavela, G.F. Ortiz, J.L. Tirado, Electrochemical and Solid-State Letters, 8 (2005) A222-A225.

[19] P. Thomas, D. Billaud, Electrochimica Acta, 46 (2001) 3359-3366.

[20] R. Alcántara, J.M. Jiménez-Mateos, P. Lavela, J.L. Tirado, Electrochemistry Communications, 3 (2001) 639-642.

[21] L. Xiao, Y. Cao, J. Xiao, W. Wang, L. Kovarik, Z. Nie, J. Liu, Chemical Communications, 48 (2012) 3321-3323.

[22] Q. Sun, Q.-Q. Ren, H. Li, Z.-W. Fu, Electrochemistry Communications, 13 (2011) 14621464.

[23] Y. Jiang, M. Hu, D. Zhang, T. Yuan, W. Sun, B. Xu, M. Yan, Nano Energy, 5 (2014) 60-66.

[24] M. Jäckle, A. Groß, The Journal of Chemical Physics, 141 (2014) 174710.

[25] B.L. Ellis, L.F. Nazar, Current Opinion in Solid State and Materials Science, 16 (2012) 168-177.

[26] S.P. Ong, V.L. Chevrier, G. Hautier, A. Jain, C. Moore, S. Kim, X. Ma, G. Ceder, Energy \& Environmental Science, 4 (2011) 3680-3688.

[27] D. Kim, E. Lee, M. Slater, W. Lu, S. Rood, C.S. Johnson, Electrochemistry Communications, 18 (2012) 66-69.

[28] D. Kim, S.-H. Kang, M. Slater, S. Rood, J.T. Vaughey, N. Karan, M. Balasubramanian, C.S. Johnson, Advanced Energy Materials, 1 (2011) 333-336.

[29] M.H. Han, E. Gonzalo, G. Singh, T. Rojo, Energy \& Environmental Science, 8 (2015) 81-102.

[30] Q. Ni, Y. Bai, F. Wu, C. Wu, Advanced Science, 4 (2017) 1600275.

[31] X. Xiang, K. Zhang, J. Chen, Advanced Materials, 27 (2015) 5343-5364.

[32] J. Hong, M. Lee, B. Lee, D.-H. Seo, C.B. Park, K. Kang, 5 (2014) 5335.

[33] K. Chihara, N. Chujo, A. Kitajou, S. Okada, Electrochimica Acta, 110 (2013) 240-246.

[34] L. Zhu, Y. Shen, M. Sun, J. Qian, Y. Cao, X. Ai, H. Yang, Chemical Communications, 49 (2013) 11370-11372. 
[35] Q. Su, G. Du, J. Zhang, Y. Zhong, B. Xu, Y. Yang, S. Neupane, W. Li, ACS Nano, 8 (2014) 3620-3627.

[36] J. Wang, C. Eng, Y.-c.K. Chen-Wiegart, J. Wang, 6 (2015) 7496.

[37] P.R. Shearing, L.E. Howard, P.S. Jørgensen, N.P. Brandon, S.J. Harris, Electrochemistry Communications, 12 (2010) 374-377.

[38] V. Yufit, P. Shearing, R.W. Hamilton, P.D. Lee, M. Wu, N.P. Brandon, Electrochemistry Communications, 13 (2011) 608-610.

[39] J.B. Robinson, J.A. Darr, D.S. Eastwood, G. Hinds, P.D. Lee, P.R. Shearing, O.O. Taiwo, B. D.J.L, Journal of Power Sources, 252 (2014) 51-57.

[40] D.S. Eastwood, V. Yufit, J. Gelb, A. Gu, R.S. Bradley, S.J. Harris, D.J.L. Brett, N.P. Brandon, P.D. Lee, P.J. Withers, P.R. Shearing, Advanced Energy Materials, 4 (2014) 1300506-n/a.

[41] D.P. Finegan, E. Tudisco, M. Scheel, J.B. Robinson, O.O. Taiwo, D.S. Eastwood, P.D. Lee, M. Di Michiel, B. Bay, S.A. Hall, G. Hinds, D.J.L. Brett, P.R. Shearing, Advanced Science, (2015) n/a-n/a.

[42] D.P. Finegan, M. Scheel, J.B. Robinson, B. Tjaden, I. Hunt, T.J. Mason, J. Millichamp, M. Di Michiel, G.J. Offer, G. Hinds, D.J.L. Brett, P.R. Shearing, Nat Commun, 6 (2015).

[43] D.P. Finegan, M. Scheel, J.B. Robinson, B. Tjaden, M. Di Michiel, G. Hinds, D.J.L. Brett, P.R. Shearing, Physical Chemistry Chemical Physics, (2016).

[44] J. Robinson, D. Finegan, T. Heenan, K. Smith, E. Kendrick, D. Brett, P.R. Shearing, Journal of Electrochemical Energy Conversion and Storage, (2017).

[45] X. Xia, J.R. Dahn, Electrochemical and Solid-State Letters, 15 (2011) A1-A4.

[46] K. Smith, J. Treacher, D. Ledwoch, P. Adamson, E. Kendrick, ECS Transactions, 75 (2017) 13-24.

[47] P.R. Shearing, L.E. Howard, P.S. Jorgensen, N.P. Brandon, S.J. Harris, Electrochemistry Communications, 12 (2010) 374-377.

[48] P.R. Shearing, D.S. Eastwood, R.S. Bradley, J. Gelb, S.J. Cooper, F. Tariq, D.J.L. Brett, N.P. Brandon, P.J. Withers, P.D. Lee, Microscopy and Analysis, 27 (2013).

[49] T.M.M. Heenan, J.J. Bailey, X. Lu, J.B. Robinson, F. Iacoviello, D.P. Finegan, D.J.L. Brett, P.R. Shearing, Fuel Cells, 17 (2017) 75-82.

[50] D.S. Eastwood, R.S. Bradley, F. Tariq, S.J. Cooper, O.O. Taiwo, J. Gelb, A. Merkle, D.J.L. Brett, N.P. Brandon, P.J. Withers, P.D. Lee, P.R. Shearing, Nuclear Instruments and Methods in Physics Research Section B: Beam Interactions with Materials and Atoms, 324 (2014) 118-123.

[51] S.J. Cooper, A. Bertei, P.R. Shearing, J.A. Kilner, N.P. Brandon, SoftwareX, 5 (2016) 203-210.

[52] J.B. Robinson, D.P. Finegan, T.M.M. Heenan, K. Smith, E. Kendrick, D.J.L. Brett, P.R. Shearing, Journal of Electrochemical Energy Conversion and Storage, 15 (2017) 011010011019.

[53] H. Maleki, G. Deng, A. Anani, J. Howard, Journal of The Electrochemical Society, 146 (1999) 3224-3229. 
[54] A.W. Golubkov, D. Fuchs, J. Wagner, H. Wiltsche, C. Stangl, G. Fauler, G. Voitic, A. Thaler, V. Hacker, RSC Advances, 4 (2014) 3633-3642.

[55] O.O. Taiwo, D.P. Finegan, D.S. Eastwood, J.L. Fife, L.D. Brown, J.A. Darr, P.D. Lee, D.J.L. Brett, P.R. Shearing, Journal of Microscopy, 263 (2016) 280-292.

[56] O.O. Taiwo, D.P. Finegan, J. Gelb, C. Holzner, D.J.L. Brett, P.R. Shearing, Chemical Engineering Science, 154 (2016) 27-33.

[57] E. Irisarri, A. Ponrouch, M.R. Palacin, Journal of The Electrochemical Society, 162 (2015) A2476-A2482.

[58] E. Kendrick, R. Gruar, M. Nishijima, H. Mizuhata, T. Otani, I. Asako, Y. Kamimura, Patent No. EP3146385A1, 2015.

[59] T.M.M. Heenan, D.P. Finegan, B. Tjaden, X. Lu, F. Iacoviello, J. Millichamp, D.J.L. Brett, P.R. Shearing, Nano Energy, (2018). 